\title{
Ethylene Signaling Modulates Herbivore-Induced Defense Responses in the Model Legume Medicago truncatula
}

\author{
Jamuna Risal Paudel and Jacqueline C. Bede \\ Department of Plant Science, McGill University, Ste-Anne-de-Bellevue, Qc, Canada, H9X 3V9, Canada \\ Submitted 30 October 2014. Accepted 15 January 2015.
}

\begin{abstract}
One or more effectors in the labial saliva (LS) of generalist Noctuid caterpillars activate plant signaling pathways to modulate jasmonate (JA)-dependent defense responses; however, the exact mechanisms involved have yet to be elucidated. A potential candidate in this phytohormone interplay is the ethylene (ET) signaling pathway. We compared the biochemical and molecular responses of the model legume Medicago truncatula and the ETinsensitive $s k l$ mutant to herbivory by fourth instar Spodoptera exigua (Hübner) caterpillars with intact or impaired LS secretions. Cellular oxidative stress increases rapidly after herbivory, as evidenced by changes in oxidized-to-reduced ascorbate (ASC) and glutathione (GSH) ratios. The caterpillar-specific increase in GSH ratios and the LS-specific increase in ASC ratios are alleviated in the $s k l$ mutant, indicating that ET signaling is required. Ten hours postherbivory, markers of the JA and JA/ET pathways are differentially expressed; $M t V S P$ is induced and $M t H E L$ is repressed in a caterpillar LS- and ET-independent manner. In contrast, expression of the classic marker of the systemic acquired resistance pathway, MtPR1, is caterpillar LS-dependent and requires ET signaling. Caterpillar LS further suppresses the induction of JA-related trypsin inhibitor activity in an ETdependent manner. Findings suggest that ET is involved in the caterpillar LS-dependent, salicylic acid/NPR1-mediated attenuation of JA-dependent induced responses.
\end{abstract}

Although the jasmonate (JA)-mediated signaling pathway primarily governs plant induced resistance (IR) in response to chewing insect herbivores, ethylene (ET) signaling cascades modulate this response in either a positive or negative manner (Zhu 2014). ET, induced by the oral secretions of the tobacco hornworm Manduca sexta, suppresses nicotine biosynthesis in Nicotiana attenuata (Voelckel et al. 2001). Therefore, some insect herbivore species have evolved one or more mechanisms to counteract plant IR by exploiting this hormonal crosstalk (Felton and Korth 2000). One or more effectors in insect saliva may activate antagonistic or synergistic phytohormone pathways to modulate the plant's JA-dependent IR (Diezel et al. 2009; Eichenseer et al. 2010; Musser et al. 2006; Paudel et al. 2013; Walling 2008; Weech et al. 2008); this is believed to be a strategy evolved by some generalist Noctuid caterpillar species to circumvent plant defenses.

Corresponding author: Jacqueline C. Bede; E-mail: jacqueline.bede@mcgill.ca; Telephone: +1.514.398.7860; Fax: +1.514.398.7897

*The $\boldsymbol{e}$-Xtra logo stands for "electronic extra" and indicates that three supplementary tables are published online.

(C) 2015 The American Phytopathological Society
As caterpillars feed, plant tissues are macerated and mandibular and labial saliva (LS) are released onto the wounded tissue. Through both the actual wounding and enzymes present in the LS, caterpillar herbivory leads to the generation of reactive oxygen species (ROS), such as hydrogen peroxide $\left(\mathrm{H}_{2} \mathrm{O}_{2}\right)$, around the wound site (Arimura et al. 2011; Maffei et al. 2006, 2012; Orozco-Cárdenas et al. 2001). At low, controlled levels, $\mathrm{H}_{2} \mathrm{O}_{2}$ is an important second messenger that leads to the activation of JAmediated signaling pathways (Arimura et al. 2011; Forman et al. 2010). However, at higher levels, $\mathrm{H}_{2} \mathrm{O}_{2}$ is detrimental to cellular function, as it can lead to lipid peroxidation and protein oxidation as well as reacting with nucleic acids (Møller et al. 2007). Thus, the induction and activation of enzymes such as peroxidases and catalases are critical to detoxify ROS (Maffei et al. 2006; Quan et al. 2008). Also, to balance the cellular redox levels, the Halliwell-Asada (ascorbate/glutathione [ASC/GSH]) cycle is activated (Noctor et al. 2012; Quan et al. 2008). In this cycle, cellular $\mathrm{H}_{2} \mathrm{O}_{2}$ levels are lowered through a series of reductionoxidation reactions that involve ASC and GSH; ASC peroxidase catalyzes the reduction of $\mathrm{H}_{2} \mathrm{O}_{2}$ to water, with the subsequent oxidation of ASC to dehydroascorbate (DHA), via the intermediate monodehydroascorbate (Foyer and Noctor 2011). DHA reductase reduces DHA to ASC, with the subsequent oxidation of GSH to generate GSSG. This last metabolite is reduced back to GSH by glutathione reductase generating NADP ${ }^{+}$ from NADPH. Besides maintaining cellular redox homeostasis, GSH is also involved in defense signaling cascades directly or as a result of protein posttranslational modifications, such as glutathionylation or S-nitrosylation (Han et al. 2013; Spoel and Loake 2011).

In response to biotic stresses, changes in oxidative stress are observed either by increases in the cellular redox metabolic pool or by shifting the ratio of oxidized-to-reduced redox metabolites (Noctor et al. 2012). Total GSH levels often increase in plants infected by pathogens or treated by salicylic acid (SA), leading to the activation of the systemic acquired resistance (SAR) pathway (Mateo et al. 2006; Mou et al. 2003; Petersen et al. 2000). Therefore, plants compromised in their ability to synthesize or accumulate GSH are more susceptible to pathogens and insect herbivores (Ball et al. 2004; Maughan et al. 2010; Parisy et al. 2007; Schlaeppi et al. 2008). For example, the Arabidopsis pad2-1 mutant that accumulates onefifth of wild-type GSH levels due to a mutation in the gene encoding $\gamma$-glutamylcysteine synthetase $(\gamma$-GCS), the enzyme that catalyzes the first step of GSH biosynthesis, is more vulnerable to herbivory by caterpillars of the Egyptian cotton leafworm, Spodoptera littoralis (Parisy et al. 2007; Schlaeppi et al. 2008). Apart from changes in the total GSH pool, a shift in the ratio of GSSG/GSH is also important in stress responses (Noctor et al. 2012). An increased ratio of GSSG/GSH and, in particular, an increase in GSSG levels is correlated with the 
activation of the JA defense pathway (Mhamdi et al. 2010). It was, therefore, unexpected that, in Arabidopsis, foliar herbivory by caterpillars of the beet armyworm $S$. exigua had no effect on total cellular GSH levels or the GSSG/GSH ratio within the first $45 \mathrm{~min}$ (Paudel et al. 2013). Also, at $35 \mathrm{~min}$, GSSG levels are reduced. In contrast, if caterpillar LS secretion is impaired, total GSH pool levels are lower compared with control plants or plants infested by caterpillars with normal labial salivary secretions. This suggests that caterpillar LS plays a role in modulating the plant cellular oxidative state in response to insect feeding. In fact, generalist noctuid caterpillars, such as $S$. exigua, have abundant oxidoreductases in their LS, such as glucose oxidase (GOX) that oxidizes glucose to produce gluconate and $\mathrm{H}_{2} \mathrm{O}_{2}$ (Bede et al. 2006; Eichenseer et al. 2010; Musser et al. 2002).

Changes in the cellular oxidative state are closely linked to the activation of the plant's defense responses. For example, GSSG accumulation activates JA biosynthesis, leading to the degradation of JA-Zim proteins and the subsequent release of MYC2/3/4 transcription factors that regulate JA-dependent gene expression (Cheng et al. 2011; Chini et al. 2007; Dombrecht et al. 2007; Fernández-Calvo et al. 2011; Lorenzo et al. 2004; Mhamdi et al. 2010; Pauwels et al. 2010; Staswick and Tiryaki 2004; Thines et al. 2007; Xu et al. 2002; Yan et al. 2009). Thus, JA-mediated IR becomes active, inducing expression of JA-related defense genes such as polyphenol oxidase (PPO) and trypsin inhibitor (TI) that interfere with the nutrient availability needed for insect growth (Constabel and Barbehenn 2008; Felton 2005; ZhuSalzman et al. 2008).

Input from other phytohormone signaling pathways that modify the JA signaling cascade are also regulated through changes in the cellular oxidative state. For example, increased GSH levels leads to the activation of the nonexpressor of pathogenesis-related protein1 (NPR1) in the SA-dependent SAR pathway that can lead to the attenuation of JA-dependent IR (Koornneef et al. 2008; Ndamukong et al. 2007; Spoel et al. 2003). In addition, changes in cellular ROS and GSH affect ET signaling pathways that can either enhance or attenuate JAregulated defense responses, in part, by modulating the SAmediated attenuation of the JA pathway (Pieterse et al. 2009; Zander et al. 2014). For example, increased $\mathrm{H}_{2} \mathrm{O}_{2}$ levels lead to the induction of ET biosynthesis (Chamnongpol et al. 1998; Vandenabeele et al. 2003). As well, enhanced GSH levels in $N t G p$ tobacco lines overexpressing the $\gamma$-GCS gene leads to the accumulation of 1-aminocyclopropane-1-carboxylate, the immediate precursor to ET (Chamnongpol et al. 1998; Ghanta et al. 2014; Vandenabeele et al. 2003; Xu et al. 2008). Thus, $\mathrm{H}_{2} \mathrm{O}_{2}$ and $\mathrm{GSH}$ may lead to elevated ET levels that modulate JA-dependent defense responses. Binding of ET to a heterodimeric receptor formed through the interaction between ET resistant 1 and ET response sensor1 on the endoplasmic reticulum inactivates the negative regulatory protein CTR1 (constitutive triple response 1) (Wang et al. 2002; Yoo et al. 2009; Zhao and Guo 2011). Upon CTR1 inactivation, the ET signal transduction cascade leads to the expression of the genes encoding ERF1 (ET response factor 1) and the ORA59 protein (octadecanoid-responsive Arabidopsis AP2/ERF) that regulate two branches of the ET-signaling pathway and integrate ET responses with the JA pathway (Lorenzo et al. 2003; Pré et al. 2008).

ET is implicated in the increased susceptibility of Arabidopsis or tomato to generalist caterpillars, such as S. littoralis and Helicoverpa zea, respectively (Stotz et al. 2000; Tian et al. 2014). In contrast, ET is correlated with plant resistance to Spodoptera frugiperda herbivory in maize (Harfouche et al. 2006). This variation in the role of ET in plant responses to caterpillar herbivory may reflect the plant or insect species or the timing of responses (early versus late). In particular, caterpillar oral secretions activate ET-responsive pathways to antagonize the JA-dependent pathway (Diezel et al. 2009). However, some plant species prioritize the JA pathway to antagonize ET-dependent pathways making the plant less appealing to the herbivore (Verhage et al. 2011).

There are multiple putative signaling nodes between the JA and ET pathways mediated by the MYC and ERF1 or ORA59 branches, respectively, that may be exploited by caterpillar herbivores (Pieterse et al. 2012; Verhage et al. 2011; Zhu et al. 2011). Chewing herbivory generally activates the MYC branch of the JA pathway. However, ET signals from herbivore feeding are integrated into the ERF1 or ORA59 branches to activate or attenuate the MYC pathway (Koornneef and Pieterse 2008; Leon-Reyes et al. 2009; Lorenzo et al. 2004; Pieterse et al. 2012, 2013; Spoel et al. 2003). For example, ET has a positive effect on JA-dependent proteinase inhibitor activity in tomato but attenuates JA-induced nicotine biosynthesis in tobacco (Kahl et al. 2000; Winz and Baldwin 2001). Zander et al. (2014) have recently shown that activation of the SA pathway antagonizes the ORA59 branch of the ET pathway. Given that previous research suggests that caterpillar LS antagonizes the JA-dependent induced responses by activating the SA signaling pathway, the involvement of ET in modulating these pathways is of key importance.

The model legume Medicago trunctula Gaernt. was used to investigate the role of ET in caterpillar LS-mediated suppression of plant IR. The unique symbiotic relationship between legumes such as $M$. truncatula and nitrogen-fixing rhizobia may lead to hormonal interactions that are distinct from other plant species, such as Arabidopsis (Anderson and Singh 2011; Oldroyd and Downie 2008). In the early infection process, GSH and related molecules act as antioxidants, whereas later in nodule development, ASC and GSH levels are not linked with oxidative stress but, rather, cues for developmental programming such as nodule senescence (Pauly et al. 2006). In comparison, less is known about the role of these redox metabolites in response to foliar insect herbivory in legumes. Early responses of legume leaves to mechanical damage include $\mathrm{H}_{2} \mathrm{O}_{2}$ and cellular $\mathrm{Ca}^{2+}$ influxes (Arimura et al. 2008; Maffei et al. 2006). However, there are distinctions between wounding caused by mechanical damage and caterpillar feeding. In legumes such as lima bean, the zone of $\mathrm{H}_{2} \mathrm{O}_{2}$ deposited on wound sites is larger when caused by caterpillar herbivory (Maffei et al. 2006). Also, ET produced in response to $S$. exigua herbivory modulates early $\mathrm{Ca}^{2+}$ fluxes in M. truncatula (Arimura et al. 2008). Wounding of M. truncatula, either through mechanical damage or caterpillar herbivory, results in a strong JA burst leading to downstream defense responses that may be influenced by other phytohormone signaling pathways (Tretner et al. 2008; Weech et al. 2008). For example, terpenoid volatiles produced in response to caterpillar herbivory that act to attract natural enemies of the insect pest are synergistically increased by ET and JA (Arimura et al. 2008; Gomez et al. 2005).

Insect salivary effectors are increasingly shown to play a critical role in activating phytohormone pathways to shape the plant's final defense response. In fact, although one current view generalizes that plant defense mechanisms against phloem feeders such as aphids is primarily mediated through the methyl salicylate/SA pathways, this standpoint is being challenged by emerging evidence supporting the important role of JA-mediated defenses in plant resistance against aphids (Kamphuis et al. 2013). Transcriptional profiles comparing plant responses to aphid herbivory in resistant ('Jester') and susceptible ('A17') M. truncatula lines show similar expression levels of SA- and ET-responsive genes but elevated levels of JA-dependent transcripts in the resistant line (Gao et al. 2007). It is important to note that evidence also points to one or more effectors in aphid saliva that activate, either singly or together, SA and ET signaling 
pathways to suppress the JA-resistance pathway (Jaouannet et al. 2014). In a similar fashion, caterpillar LS may modulate JAmediated defense responses through activation of phytohormone pathways.

In this study, oxidative stress, hormone levels, and gene and protein markers of JA-dependent IR were compared in wildtype $M$. truncatula and the ET-insensitive $s k l$ mutant that has a mutation in MtSkl1, an ortholog of AtEIN2 (Penmetsa and Cook 1997; Penmetsa et al. 2008). M. truncatula plants were infested by fourth instar caterpillars of $S$. exigua, a generalist pest species with high LS GOX activity (Merkx-Jacques and Bede 2005). To understand the potential role of LS in these interactions, plant responses to caterpillars with normal versus impaired labial salivary secretions (cauterized) were compared.

\section{RESULTS AND DISCUSSION}

\section{Caterpillar LS affects Medicago truncatula cellular} oxidative stress.

In both wild-type $M$. truncatula and the ET-insensitive $s k l$ mutant, total ASC does not change in the initial 45 min after
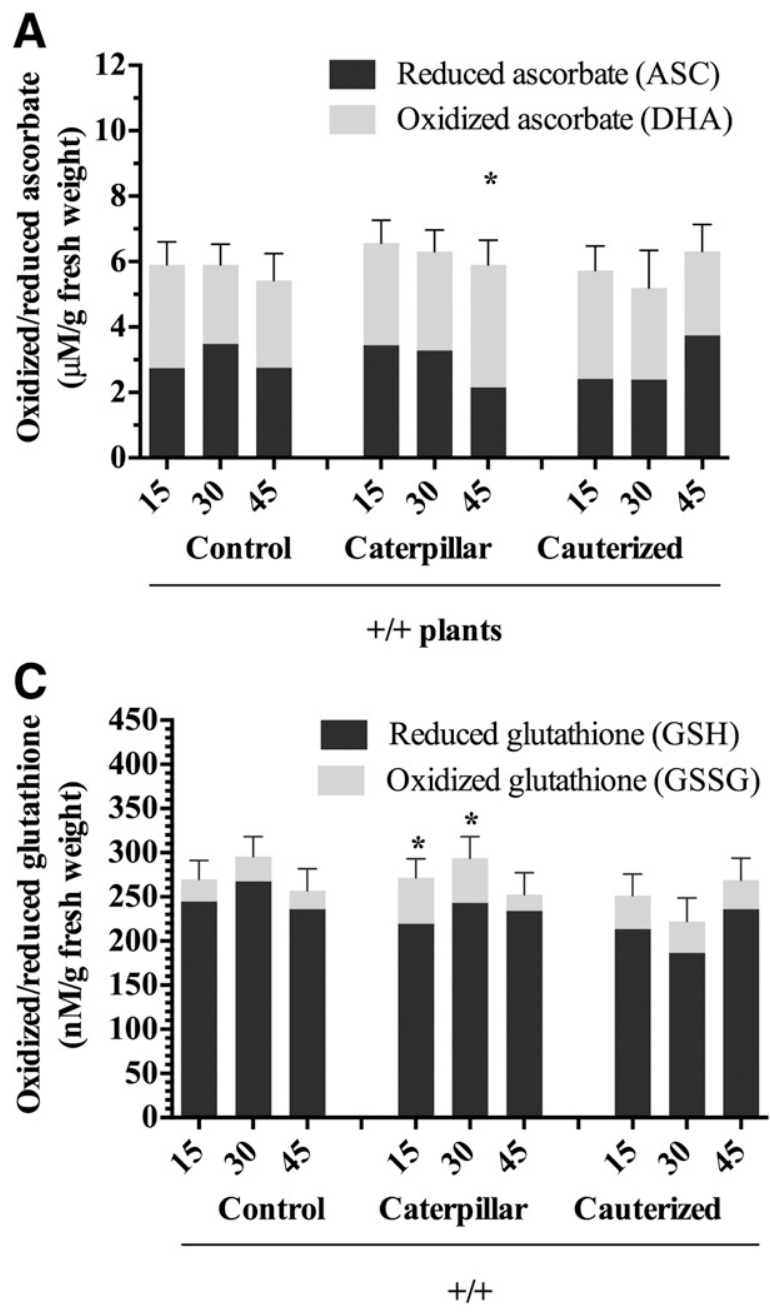

herbivory (Fig. 1A and B). As well, the ratio of oxidized-toreduced ASC (DHA/ASC) does not change in control plants or in plants subject to herbivory by caterpillars with impaired labial salivary secretions over the 45-min time course. In comparison, herbivory by caterpillars with normal labial salivary secretions results in an increase in the cellular DHA/ASC ratio at $45 \mathrm{~min}$ (Fig. 1A). This LS-specific response is not seen in the $s k l$ mutant, indicating that caterpillar LS-associated changes in plant redox metabolites require ET signaling.

Total and reduced GSH levels do not change in response to caterpillar herbivory over the first $45 \mathrm{~min}$ in control and cauterized treatment in both the $M$. truncatula wild type and $s k l$ mutant plants (Fig. 1C and D). In response to herbivory by caterpillars with normal labial salivary secretions, a transient increase in GSSG levels and, therefore, in the GSSG/GSH ratio is observed in wounded leaves of wild-type $M$. truncatula within 15 to $30 \mathrm{~min}$ of the initiation of herbivory as compared with control plants (Fig. 1C). GSSG decreases to basal levels at 45 min. In contrast, GSH, GSSG, or total GSH levels do not change in the $s k l$ mutant in response to caterpillar feeding (Fig. 1D).
B

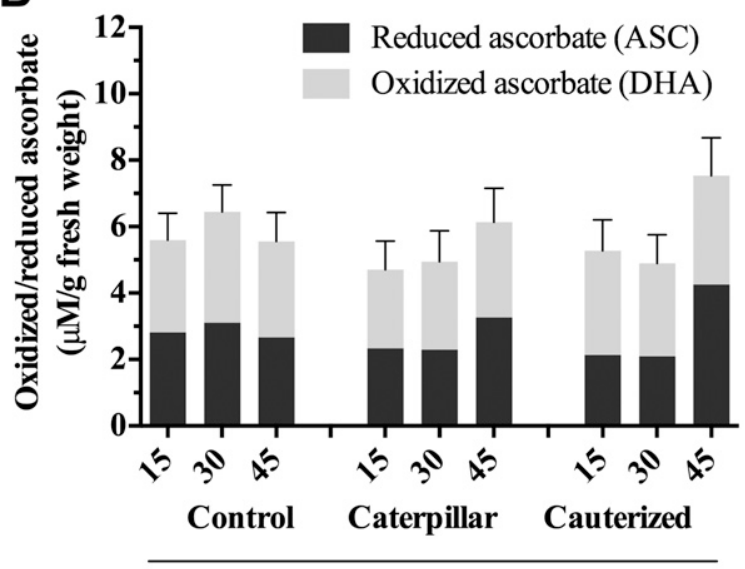

D

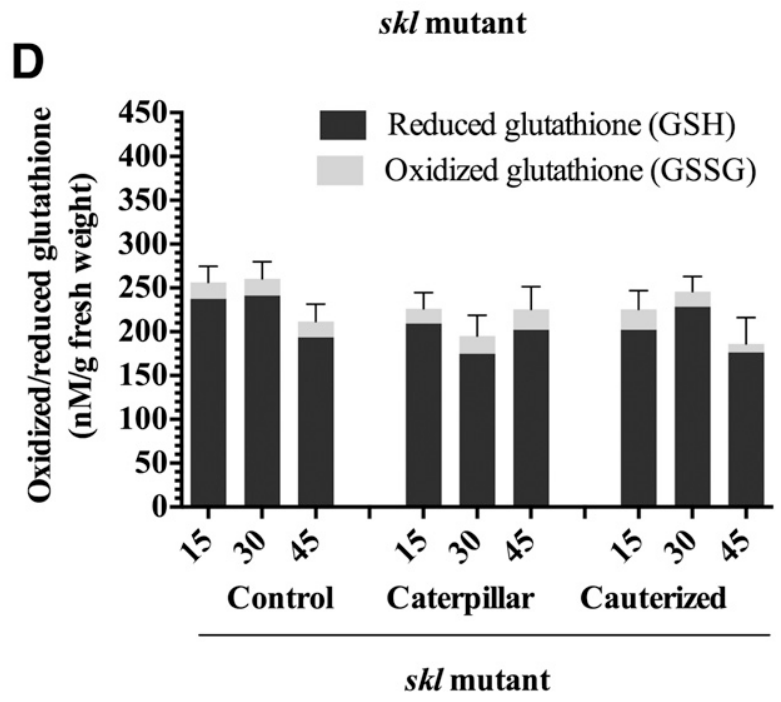

Fig. 1. Time course of redox metabolites in Medicago truncatula plants in response to Spodoptera exigua caterpillar herbivory. Six-week-old M. truncatula wildtype (+/+) or $s k l$ mutant plants were subjected to herbivory by fourth instar $S$. exigua caterpillars. To assess the involvement of caterpillar labial saliva (LS) in plant responses, two populations of caterpillars were used, i.e., those with intact (caterpillar) or impaired (cauterized) LS secretion. A, Ascorbate (ASC) levels in M. truncatula wild type plants or B, skl mutants. Solid bars represent reduced ASC and open bars represent oxidized ASC (DHA). At 45 min, the ratio of DHA/ASC is significantly increased in wild-type plants infested by caterpillars with intact LS secretions. C, Glutathione (GSH) levels in M. truncatula wild type plants and D, $s k l$ mutants. Solid bars represent reduced GSH and open bars represent oxidized glutathione (GSSG). In wild-type plants, GSSG and, thus, the ratio of GSSG/GSH is significantly increased in plants subject to herbivory by caterpillars with intact salivary secretions at 15 to 30 min after infestation as compared with control plants. Bars represent the means of five to eight independent biological replicates \pm standard error. Within each genotype, redox metabolites were analyzed by two-way analysis of variance (ANOVA). When an interaction was detected (time $\times$ treatment), samples within each treatment were analyzed by one-way ANOVA, followed by Tukey honest significant difference post hoc test to identify the significant effect $(P \leq 0.05)$. Significant differences are denoted by asterisks. 
Activation of the ASC/GSH cycle in response to pathogen and herbivore attack is critical to maintain cellular redox status (Ball et al. 2004; Espunya et al. 2012; Parisy et al. 2007; Schlaeppi et al. 2008). In fact, pad2-1 mutants that have lower GSH levels are more susceptible to caterpillar herbivory highlighting the important role of the ASC/GSH cycle in plant resistance (Parisy et al. 2007). Elevated total and GSH levels in response to biotrophic pathogen infection activate NPR1, an important modulator of the SAR pathway (Mateo et al. 2006; Mou et al. 2003). GSH may also be involved in regulating signal transduction pathways by affecting protein posttranslational modification (Han et al. 2013; Spoel and Loake 2011). In the current study and previously, we investigated early redox response of two model plants, M. truncatula and A. thaliana, to caterpillar herbivory. In Arabidopsis, S. exigua caterpillar LS helps maintain a reductive cellular environment, since total and GSH levels are observed in plants infested by caterpillars with impaired labial salivary secretions (Paudel et al. 2013). In contrast, even though the current study shows no effect on the total level of either ASC or GSH, the ratio of DHA/ASC, as well as the level of GSSG and, hence, the ratio of GSSG/GSH, increases in $M$. truncatula as an early response to caterpillar feeding. These caterpillar-specific (GSH) and LS-dependent (ASC) changes are not observed in the $s k l$ mutant, indicating that ET signaling is needed for the activation of the ASC/GSH cycle in response to caterpillar herbivory in M. truncatula.

\section{The JA burst observed upon caterpillar herbivory} is not affected by ET.

As expected, a JA burst is observed in response to caterpillar herbivory (Fig. 2A and B). Free JA and bioactive JA-Ile are strongly elevated in both genotypes of $M$. truncatula, wild type and $s k l$ mutants, upon S. exigua caterpillar feeding (Fig. 2A and B). Therefore, in M. truncatula, ET does not mediate the early JA burst in response to caterpillar feeding. Also, a LS-specific difference in JA levels is not observed in M. truncatula, unlike previous observations in Arabidopsis (Lan et al. 2014; Weech et al. 2008). In Arabidopsis, caterpillar LS impairs the plant's ability to mount a full JA burst. In $M$. truncatula, the caterpillarspecific increase in 12-oxo-phytodienoic acid (OPDA), a precursor in the JA pathway and bioactive molecule, or SA are not observed (Fig. 2C; SA data not shown). Abscisic acid (ABA) levels are unaffected by caterpillar herbivory in wild-type plants but increase in $s k l$ mutants fed upon by caterpillars with intact labial salivary secretions, suggesting that LS-induced ET suppresses ABA levels (Fig. 2D). In Arabidopsis, ABA is involved in priming systemic leaves in response to herbivory by specialist caterpillars of the cabbage white butterfly Pieris rapae (Vos et al. 2013).

\section{Markers of the JA, SA, and ET pathways} are differentially expressed in response to caterpillar LS.

As expected from previous research (Darwish et al. 2008), Rubisco activase (MtRCA), strictosidine synthase-like (MtSTRlike), and E3 ubiquitin-protein ligase (MtXBAT31-like) expression is lower in response to caterpillar herbivory (Fig. 3A, $\mathrm{B}$, and D); a LS-specific difference is not observed. In Nicotiana attenuata, RCA has been implicated in the redirection of defensive phytohormones, such as JA-Ile, into the less active methyl JA (Mitra and Baldwin 2014). Therefore, this observed downregulation of MtRCA expression in response to caterpillar herbivory may reflect the plant's strategy to avoid this redirection and activate plant defenses. Expression of the receptor protein kinase $(M t R P K)$ gene is also suppressed in response to insect
A

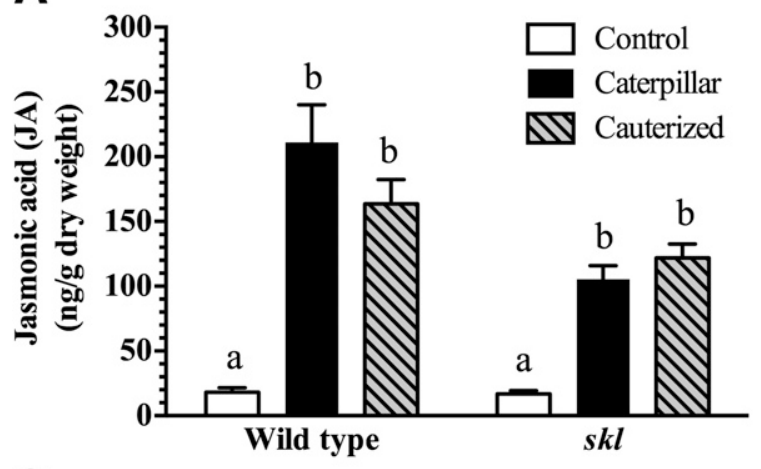

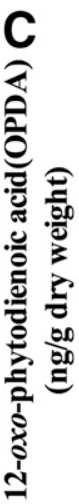

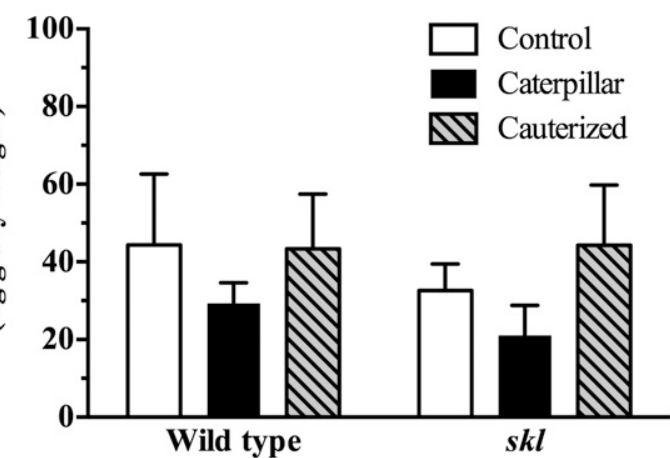

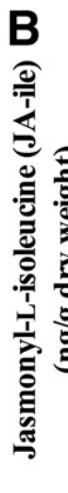

D

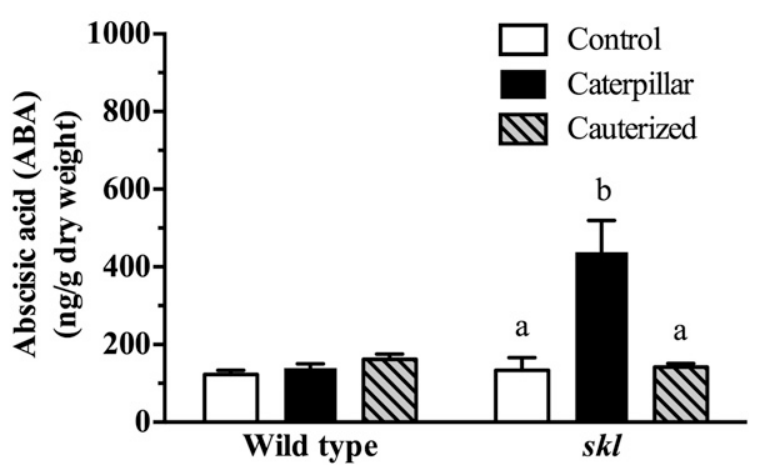

Fig. 2. Medicago truncatula phytohormone levels in response to Spodoptera exigua caterpillar herbivory. Six-week-old M. truncatula wild type or skl mutant plants were subjected to herbivory by fourth instar $S$. exigua caterpillars for $10 \mathrm{~h}$. To assess the involvement of caterpillar labial saliva (LS) in plant responses, two populations of caterpillars were used, i.e., those with intact (caterpillar, black bars) or impaired (catuterized, hatched bars) LS secretions. A, Foliar levels of jasmonate (JA), B, jasmonyl-isoleucine (JA-Ile), C, 12-oxo-phytodienoic acid (OPDA), and D, abscisic acid (ABA) were compared. Bars represent the means of three independent biological replicates \pm standard error. Hormone levels were analyzed by one-way analysis of variance within each genotype followed by a Tukey honest significant difference posthoc test. Letters indicate significant difference between treatments $(P \leq 0.05)$. 
feeding (Fig. 3C), contrary to what was observed by Darwish et al. (2008). This likely reflects differences between early (1 h) (Darwish et al. 2008) and later (10 h, this study) regulation of this gene. Caterpillar-dependent suppression of MtSTR-like, MtRPK, and $M t X B A T 31$-like is alleviated in the ET-insensitive skl mutants. However, for MtSTR-like and MtXBAT31-like, this may reflect the already low basal consititutive levels.

Vegetative storage protein (MtVSP) and hevein-like protein (MtHEL, PR4) are markers of the JA and JA/ET pathways, respectively (Pré et al. 2008). In Arabidopsis, AtHel expression integrates signals from both the JA and ET pathway via the transcription factor ORA59 (Pré et al. 2008). In comparison, AtVSP1 expression is ORA59-independent. Similar to the JA profile (Fig. 2A and B), caterpillar feeding enhances MtVSP expression, confirming the involvement of the MYC branch of the JA-mediated defense pathway (Fig. 3E). A caterpillar LSdependent regulation is not observed, in agreement with previous observation of MYC-dependent gene expression in Arabidopsis (Lan et al. 2014). A similar expression pattern in the ETinsensitive $s k l$ mutant was expected, since JA but not ET plays a central role in the induction of the VSP gene (Pré et al. 2008; Verhage et al. 2011). In contrast, MtHEL transcripts are suppressed in response to $S$. exigua herbivory in both plant genotypes (Fig. 3F). The suppression of AtHEL by the antagonistic SA-mediated pathway is independent of NPR1 (Ndamukong et al. 2007). Therefore, the observed suppression of MtHEL could be due to the antagonistic effect of the caterpillar-induced
MYC branch on the AP2/ERF branch of the JA pathway (Lorenzo et al. 2004; Pieterse et al. 2012). In contrast, the antagonism mediated by the MYC branch on AtERF1 expression is not observed in Arabidopsis subject to $S$. exigua caterpillar herbivory or in tomato plants infested by $H$. zea caterpillars (Paudel et al. 2013; Tian et al. 2014). Therefore, this may represent the differential regulation of the ORA59 and ERF1 branches of the JA/ET pathway in different plant species in response to caterpillar herbivory (Verhage et al. 2011). Zander et al. (2014) have recently shown that SA mediates the inhibition of the ORA59 branch of the ET pathway through TGA transcription factors in Arabidopsis. However, if this was the case in Medicago spp., we might expect a caterpillar LS-dependent difference, which we did not observe. However, this may reflect species-related or timing differences, as suggested by Zander et al. (2014).

Pathogenesis-related protein $1(M t P R l)$ is a marker of the NPR1-dependent SAR pathway (Pieterse et al. 2012; Pré et al. 2008). LS-specific induction of MtPRl is observed in response to caterpillar feeding. This suggests that one or more effectors in the caterpillar LS activates the SAR pathway (Fig. 3G). In Arabidopsis, the LS-specific induction of the AtPRl gene is also observed late $(36 \mathrm{~h})$ but not early $(10 \mathrm{~h})$ after the initiation of S. exigua herbivory (Lan et al. 2014; Paudel et al. 2013). MtPRl expression is ET-dependent (Fig. 3G), in agreement with previous observations that ET enhances the plant response to SA-dependent gene expression (Leon-Reyes et al. 2009).
A
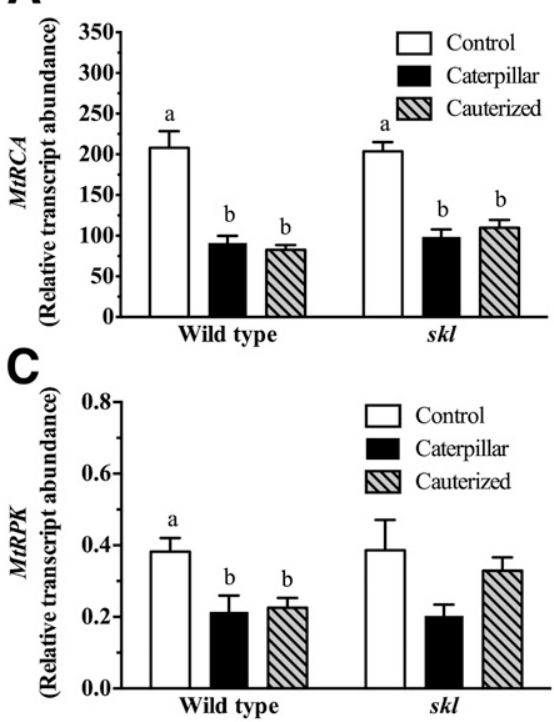

E

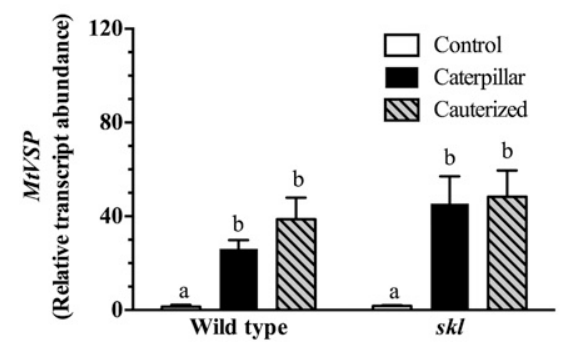

B

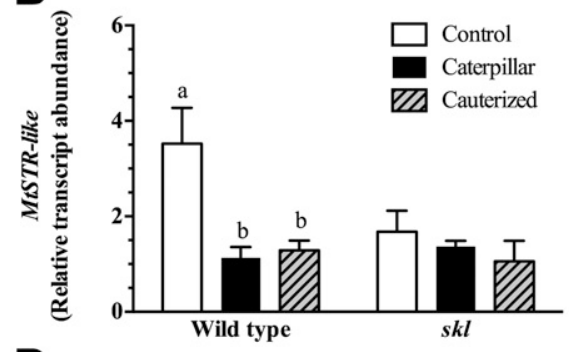

D

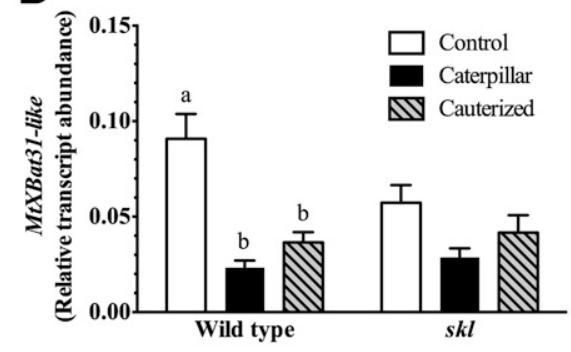

$\mathbf{F}$

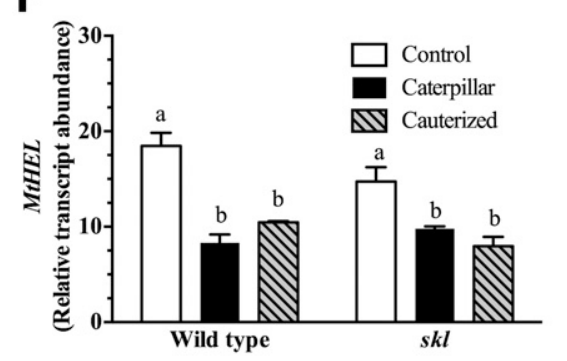

G

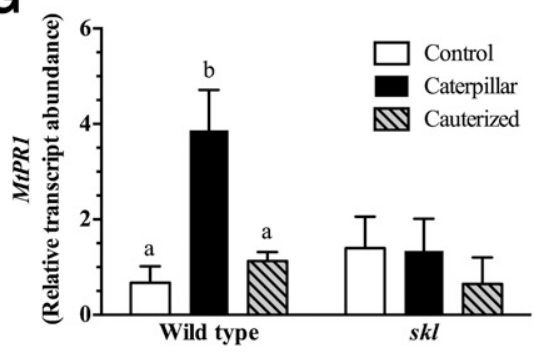

Fig. 3. Medicago truncatula defense-related gene expression in response to Spodoptera exigua caterpillar herbivory. Six-week-old M. truncatula wildtype or skl mutant plants were subjected to herbivory by fourth instar $S$. exigua caterpillars for $10 \mathrm{~h}$. To assess the involvement of caterpillar labial saliva (LS) in plant responses, two populations of caterpillars were used, i.e., those with intact (caterpillar, black bars) or impaired (catuterized, hatched bars) LS secretions. A, Relative expression of $M t R C A, \mathbf{B}, M t S T R$-like, $\mathbf{C}, M t R P K, \mathbf{D}, M t X B A T 31$-like, E, MtVSP, F, MtHEL, and G, MtPR1 genes were compared in caterpillarwounded or undamaged leaves from control plants. Expression levels were normalized to the constitutively expressed $M t G A D P H$ gene. Bars represent the means of four to five independent biological replicates \pm standard error. Transcript expression levels were analyzed by one-way analysis of variance within each genotype followed by a Tukey honest significant difference posthoc test. Letters indicate significant difference between treatments $(P \leq 0.05)$. 
Caterpillar LS-dependent suppression of TI activity.

In wild-type $M$. truncatula, TI is significantly higher in plants infested by caterpillars with impaired labial salivary secretions than in plants attacked by normal caterpillars or control plants, suggesting that one or more effectors in $S$. exigua caterpillar LS prevents the plant from mounting a full JA defense response (Fig. 4A).The LS-specific suppression of $\mathrm{TI}$ is abolished in the ET-insensitive $s k l$ mutant. The activity of the defense-related protein PPO is not affected by caterpillar herbivory in either genotype (Fig. 4B).

\section{Conclusions.}

In addition to rapid cellular $\mathrm{Ca}^{2+}$ influx and changes in membrane potential, one of the first plant responses to caterpillar herbivory is changes to cellular redox balance (Maffei et al. 2006). This may manifest itself by increases in total ASC or GSH levels or shifts in the balance of oxidized-to-reduced metabolites (Noctor et al. 2012). In M. truncatula, total ASC and GSH levels do not change in response to caterpillar herbivory. Instead, changes in the DHA/ASC and GSH ratios, indicative of oxidative stress, are observed within the first $45 \mathrm{~min}$ after caterpillar herbivory (Fig. 1A and C). With ASC, the LSspecific increase in ASC ratio is not observed in the skl mutant, suggesting that this caterpillar LS-dependent difference requires ET signaling (Fig. 1B). When compared with control plants, plants infested by caterpillars with intact labial salivary secretions have a transient increase in GSSG and also, therefore, the GSSG/GSH ratio within the first half hour after attack (Fig. 1C). This change in oxidative stress is not observed in the $s k l$ mutant (Fig. 1D). This is of interest since, in Arabidopsis, GSSG levels are positively correlated with JA defense responses and points to the role of ET in the regulation of cellular redox changes (Mhamdi et al. 2010). Therefore, in M. truncatula, caterpillar herbivory results in an increase in oxidative stress within the first hour. This contrasts with Arabidopsis, in which caterpillar LS suppresses changes in oxidative stress seen in plants subject to attack by caterpillars with impaired labial salivary secretions (Paudel et al. 2013). These apparently contradictory strategies may reflect differences in plant defense responses, since, in Arabidopsis, GSH is a precursor to key defensive compounds, i.e., glucosinolates (Halkier and Gershenzon 2006), or may reflect the influence of host plant nutritional quality (i.e., Arabidopsis versus M. truncatula) on one or more effector levels in the caterpillar LS (Afshar et al. 2010; Merkx-Jacques and Bede 2005; J. C. Bede unpublished data).
Later plant responses to caterpillar herbivory involve changes in phytohormones, gene expression, and defense-related proteins. Ten hours after the initiation of herbivory, a strong JA burst is observed. Unlike Arabidopsis, LS-specific differences in JA phytohormones, i.e., jasmonic acid or JA-Ile, are not observed (Fig. 2A and B) (Lan et al. 2014). In contrast, similar to previous studies in Arabidopsis, caterpillar LS-related differences in SA hormone levels are not observed (Lan et al. 2014; Weech et al. 2008).

Caterpillar herbivory results in the suppression of $M t R C A$, MtSTR-like, and MtXBAT31-like gene expression (Darwish et al. 2008). MtVSP, a marker of the JA pathway, is induced in response to caterpillar herbivory in a LS- and ET-independent manner (Fig. 3E). In contrast, levels of MtHEL, a marker of the JA/ET pathway, is lower in response to caterpillar herbivory (Fig. 3F). Since this pattern of expression is also LS- and ETindependent, this may reflect the involvement of other antagonistic phytohormone pathways, such as the gibberellin/della pathway, in these plant-insect interactions. Of key interest is the expression pattern of the SA marker gene MtPRl. As in Arabidopsis, caterpillar LS-dependent PRI expression is observed in M. truncatula (Fig. 1G) (Paudel et al. 2013). This is alleviated in the $s k l$ mutant, illustrating the role of ET in the positive enhancement of SA-dependent MtPR1 gene expression, as has been previously shown in Arabidopsis (LeonReyes et al. 2009). This result indicates that, in response to caterpillar herbivory, both SA and ET pathways are activated in addition to the expected JA signaling pathway. Finally, caterpillar LS suppresses the induction of the important defensive protein TI in an ET-dependent manner. Together, these results support the model that caterpillar LS activates the SA/ NPR1 pathway to interfere with plant induced resistance and points to the importance of ET in modulating this crosstalk (Fig. 5).

\section{MATERIALS AND METHODS}

\section{Chemicals.}

All chemicals were purchased from Sigma Chemical Co., unless otherwise noted.

\section{Plant growth conditions.}

M. truncatula cv. Jemalong A17 seeds were scarified in concentrated sulfuric acid (12 $\mathrm{min})$ and were then thoroughly washed with sterile distilled water. Two genotypes were
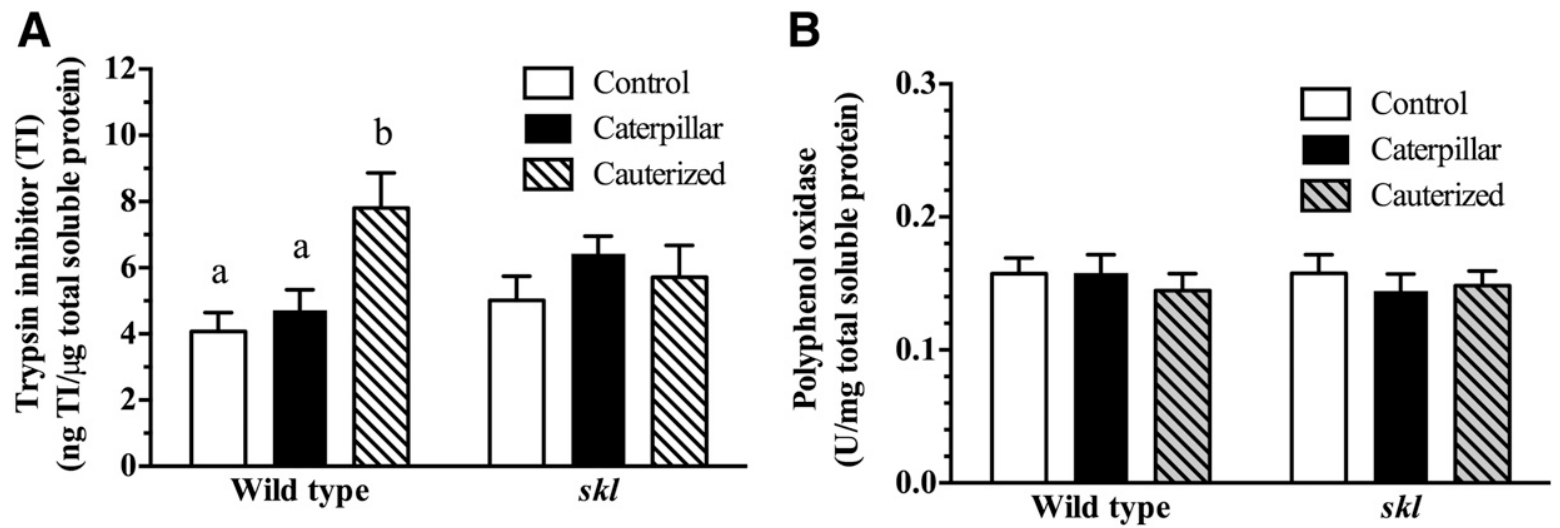

Fig. 4. Medicago truncatula defense-related protein levels and activity in response to Spodoptera exigua caterpillar herbivory. Six-week-old M. truncatula wild type or $s k l$ mutant plants were subjected to herbivory by fourth instar S. exigua caterpillars for $34 \mathrm{~h}$. To assess the involvement of caterpillar labial saliva (LS) in plant responses, two populations of caterpillars were used, i.e., those with intact (caterpillar, black bars) or impaired (catuterized, hatched bars) LS secretions. A, Trypsin inhibitor (TI) levels and B, polyphenol oxidase (PPO) activity were compared in caterpillar-wounded or undamaged leaves from control plants. Bars represent the means of 10 to 12 independent biological replicates \pm standard error. TI levels and PPO activity were analyzed by one-way analysis of variance within each genotype, followed by a Tukey honest significant difference posthoc test. Letters indicate significant difference between treatments $(P \leq 0.05)$. 
planted; wild type and the ET-insensitive $s k l$ mutant. After stratification at $4^{\circ} \mathrm{C}$ for 2 days followed by 2 days at room temperature, seedlings were sown in pasteurized Agro mix (Fafard). Plants were kept in growth cabinets (light intensity $260 \mu \mathrm{Em}^{-2} \mathrm{~s}^{-1}, 16 \mathrm{~h}$ of light and $8 \mathrm{~h}$ of dark, $22^{\circ} \mathrm{C}$ ) and were watered three times weekly with dilute 20:20:20 NPK fertilizer (1.05 g of NPK per 7 liters $\mathrm{H}_{2} \mathrm{O}$ ). At three weeks, seedlings were transplanted to 1-liter pots.

\section{Caterpillar maintenance conditions.}

Caterpillars of the beet armyworm S. exigua were reared on a wheat germ-based artificial diet (Bio-Serv). The colony was maintained in growth cabinets $\left(28^{\circ} \mathrm{C}, 60 \%\right.$ relative humidity, $16 \mathrm{~h}$ of light and $8 \mathrm{~h}$ of dark). Fourth instar caterpillars were used in the experiments. Caterpillars were fed on M. truncatula cv. Jemalong A17 (wild-type "feeder" plants) for $24 \mathrm{~h}$ before being transferred to experimental plants.

\section{Ablation of the caterpillar spinneret (cauterization).}

To evaluate the role of caterpillar LS in the modulation of plant IR, two populations of caterpillars were used; one with normal (mock) and the other with impaired (cauterized) labial salivary secretions. In the cauterized caterpillars, the spinneret was burned shut with a hot probe to prevent the secretion of LS (Musser et al. 2006). Since GOX is a key enzyme in caterpillar LS, a horseradish peroxidase (Hrp)-o-diaminobenzidine (DAB)coupled reaction that detects GOX activity was performed to evaluate the success of the cauterization. Caterpillars, both mock and cauterized, fed on glass fiber discs saturated with a glucose/ sucrose solution $(1: 1 ; 50 \mathrm{mg} / \mathrm{ml}$ each). After visible feeding, DAB tetrahydrochloride and $\operatorname{Hrp}(2.5 \mathrm{U})$ were added to the disc. The presence of GOX was indicated by a brown precipitation.

\section{Experimental design.}

Five- to six-week-old $M$. truncatula (wild type or skl mutant) plants received one of three treatments, either caterpillars with normal salivary secretions, cauterized caterpillars, or plants remained untouched (control). Treatments were performed at night (i.e., $1 \mathrm{~h}$ after lights were shut off in the growth cabinets), since these caterpillars exhibit a predominantly nocturnal feeding behavior. For herbivore treatments, three fourth-instar caterpillars were introduced per plant. To contain the caterpillars, a modified transparent bottle was fitted to the pot for all plants 1 week before the experiment, with netting used to cover the open tops. For the redox metabolite analysis, leaf samples were collected at 15-min intervals within the first 45 min following herbivory. For hormone analysis, whole plants cut at the crown were obtained after $10 \mathrm{~h}$ of herbivory. Caterpillar-fed leaves were collected for gene expression and defense protein analysis at 10 and $34 \mathrm{~h}$ after herbivory, respectively. Samples were immediately frozen in liquid nitrogen and were stored at $-80^{\circ} \mathrm{C}$ until analysis. For ASC and GSH analysis, samples were collected from three independent plants and the experiment was repeated three times to generate nine biological replicates. Samples were collected from two to three independent plants and the experiment was repeated three to five times to generate at least ten biological replicates for analysis of phytohormones and defensive proteins or five biological replicates for gene expression studies.

\section{Analysis of redox metabolites ASC and GSH.}

ASC and GSH content of the leaf samples was analyzed following the protocol described by Queval and Noctor (2007). Frozen leaf samples were ground in liquid nitrogen and were extracted in acidic medium $(0.2 \mathrm{~N} \mathrm{HCl})$, followed by neutralization with $0.2 \mathrm{~N} \mathrm{NaOH}$. Spectrophotometric analyses of total, oxidized, and reduced forms of ASC and GSH were performed in a 96-well plate format, using the Tecan Infinite M200 Pro microplate reader as described below.

\section{ASC.}

In triplicate, samples were measured at $265 \mathrm{~nm}$ to determine levels of reduced ASC. Samples were then incubated with ASC oxidase $(0.2 \mathrm{U})$ in $0.1 \mathrm{M}$ sodium phosphate buffer $\left(\mathrm{NaH}_{2} \mathrm{PO}_{4}\right)$, $\mathrm{pH} 5.6$, for $8 \mathrm{~min}$ at room temperature. The difference in absorbance at $265 \mathrm{~nm}$ was used to calculate the level of reduced ASC in the sample (Queval and Noctor 2007). To determine total ASC levels, samples were incubated with $1 \mathrm{mM}$ dithiothreitol (DTT) in $67.2 \mathrm{nM}$ sodium phosphate buffer, $\mathrm{pH} 7.5$, for $30 \mathrm{~min}$ at room temperature. DTT reduces DHA to ASC. An ASC standard curve (ranging from 40 to $240 \mu \mathrm{M}$ ) and blanks were included in each plate.

\section{GSH.}

GSH content was measured by the recycling assay method described by Rahman et al. (2006) and Queval and Noctor (2007). For total GSH (GSH + GSSG), sample extracts were incubated with 5,5'-dithiobis(2-nitrobenzoic acid) (DTNB; $0.6 \mathrm{mM}$ ) in $0.1 \mathrm{M}$ sodium phosphate buffer, $\mathrm{pH}$ 7.5. Glutathione reductase $(0.015 \mathrm{U})$ and NADPH $(0.75 \mathrm{mM})$ converts GSSG to GSH. GSH reacts with DTNB to produce GS-TNB, which then converts into TNB (5-thio-2-nitrobenzoic acid), which is measured at $412 \mathrm{~nm}$. TNB levels were measured as absorbance at $412 \mathrm{~nm}$ at 5 -s intervals for $2 \mathrm{~min}$. The slope of the first $90 \mathrm{~s}$ was used to calculate GSH concentration, using a standard curve of free GSH (ranging from 1 to $50 \mu \mathrm{M}$ ).

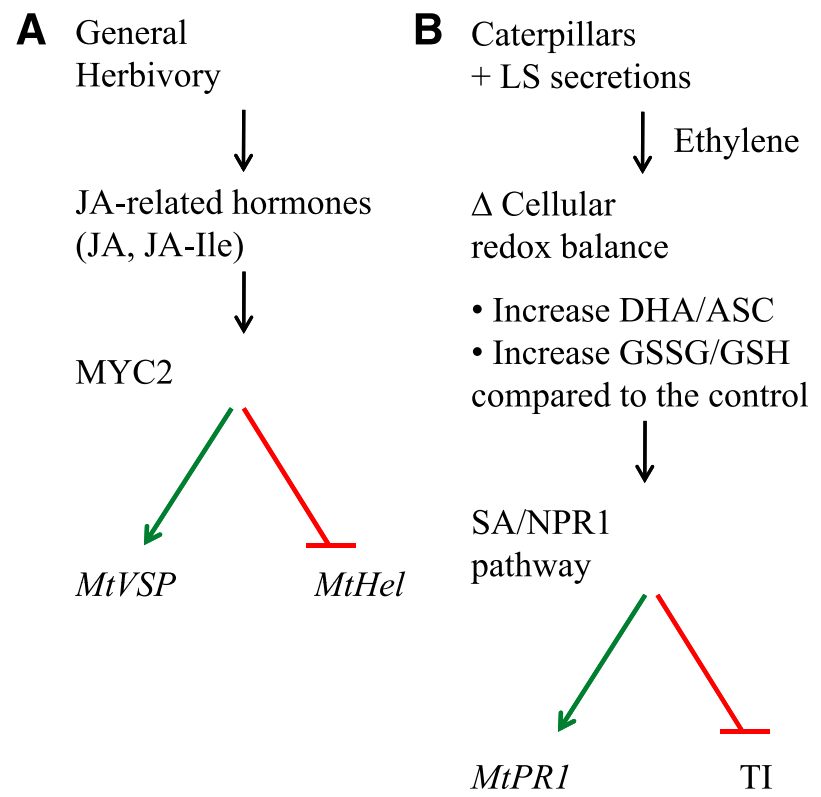

Fig. 5. Model of the role of ethylene (ET) in the caterpillar labial saliva (LS)mediated modulation of jasmonate (JA)-dependent defense responses in Medicago truncatula. A, In response to Spodoptera exigua caterpillar herbivory, a JA burst is observed, leading to the induction of MtVSP and suppression of $\mathrm{MtHel}$ expression. B, Caterpillar LS modulates plant responses. Rapidly after the onset of herbivory, a LS-dependent increase in oxidized-to-reduced ascorbate is observed. Also, an increase in the oxidized glutathione/glutathione (GSSG/GSH) ratio is observed in response to herbivory by caterpillars with intact LS secretions as compared with control plants. LS-dependent induction of the systemic acquired resistance marker MtPRI and the suppression of the defensive protein trypsin inhibitor is observed. These differences are alleviated in the $s k l$ mutant indicating that ET signaling plays a role in the caterpillar LSmediated modulation of plant defense responses. 
To measure GSSG, the neutralized sample was incubated with $1 \mu \mathrm{l}$ of 2-vinylyridine (VPD) for $30 \mathrm{~min}$ at room temperature. VPD precipitates GSH, which is then removed by centrifugation at $15,700 \times g$ for $5 \mathrm{~min}$. The VPD-treated extract was diluted with $0.1 \mathrm{M}$ sodium phosphate buffer, $\mathrm{pH} 7.5$, and the concentration of GSSG was measured by the recycling assay, as described above. A standard curve generated using free GSSG (ranging from 0.1 to $2.5 \mu \mathrm{M}$ ) was used to calculate GSSG concentration. Reduced GSH in the sample was calculated by subtracting $2 \times$ GSSG from the total GSH. Samples were analyzed in triplicate, and negative controls were included in every plate.

\section{Hormone analysis.}

JA, JA-Ile, OPDA, SA, and ABA levels were analyzed in the Proteomics and Mass Spectrometry facility at the Danforth Plant Science Center (St. Louis, MO, U.S.A.) by liquid chromatography coupled to tandem mass spectrometry. Samples were ground, using a TissueLyser for 2 min at a frequency of $15 \mathrm{~Hz} \mathrm{~s}^{-1}$. Hormones were extracted from lyophilized leaf samples in ice cold methanol $(\mathrm{MeOH}) /$ acetonitrile $(\mathrm{ACN})(1: 1$, $\mathrm{vol} / \mathrm{vol})$. Samples were spiked with deuterium-labeled internal standards of SA (D 5 -SA), ABA (D $\left.{ }^{6}-\mathrm{ABA}\right)$, and JA (D $\left.{ }^{2}-\mathrm{JA}\right)$. Supernatants were collected after centrifugation at $16,000 \times g$ and extraction of pellets was repeated. Pooled supernatants were evaporated using a speedvac, before redissolving the pellets in $200 \mu \mathrm{l}$ of $30 \% \mathrm{MeOH}$ for hormone analysis. Chromatographic separation of metabolites was accomplished on a monolithic $\mathrm{C}_{18}$ column (Onyx, $4.6 \times 100 \mathrm{~mm}$; Phenomenex), using a binary solvent of $0.1 \%$ acetic acid in high-performance liquid chromatography-grade water (vol/vol) (solvent A) and $90 \%$ ACN with $0.1 \%$ acetic acid ( $\mathrm{vol} / \mathrm{vol}$ ) (solvent $\mathrm{B}$ ) with a flow rate of $1 \mathrm{ml} \mathrm{min}^{-1}$. A 4000-QTRAP (AB Sciex) was used to acquire mass spectrometry spectra. Parameters for analysis were set as follows: electron spray ionization in the negative mode (TurbolonSpray), capillary voltage $-4,500$, nebulizer gas $\left(\mathrm{N}_{2}\right) 50$ arbitrary units (a.u.), heater gas 50 a.u., curtain gas 25 a.u., collision activation dissociation high, temperature $550^{\circ} \mathrm{C}$. Compounds were detected using multiple reaction monitoring transitions that were optimized for each phytohormone and deuterium-labeled standards (Pan et al. 2010). Concentrations were determined from the standard curves of known phytohormones.

\section{Gene expression analysis.}

RNA extraction and reverse transcription. Total RNA was extracted from samples using the RNeasy kit (Qiagen), following the manufacturer's instructions. After determining RNA concentration and quality (260/280 of approximately 2), cDNA was generated using a QuantiTect reverse transcription kit (Qiagen). Before reverse transcription, genomic DNA in the samples was degraded using the DNase included in the kit. The absence of genomic DNA contamination was confirmed using primers $\left(5^{\prime}-\right.$ CTCTCCTGCATTTCCACTTTC-3' and 5'-TTCTTGACCC TACCAAACATCA-3') that amplify an introgenic region by polymerase chain reaction (PCR) (Darwish et al. 2008). As a positive control, genomic DNA was used as template. cDNA samples were diluted 1:10 and transcript abundance was measured by quantitative real time (qRT)-PCR.

$q R T-P C R$. Gene expression was analyzed by SYBR greenbased qRT-PCR, using a MX3000p thermo-cycler (Stratagene). Reactions contained 1× SYBR Green with low ROX (Absolute Blue; Thermo Scientific), cDNA, and $1 \mu \mathrm{M}$ of both forward and reverse primers. Thermocycler conditions were as follows: $95^{\circ} \mathrm{C}$ for $10 \mathrm{~min}, 40$ cycles of denaturation at $95^{\circ} \mathrm{C}$ for $30 \mathrm{~s}$, annealing for $30 \mathrm{~s}\left(55\right.$ to $60^{\circ} \mathrm{C}$ for the different genes of interest [GOI]), and elongation at $70^{\circ} \mathrm{C}$ for $30 \mathrm{~s}$. Primers for the GOI and reference gene $M t G A D P H$ are listed in Supplementary Table 1. Five biological replicates $(n=5)$ for each treatment from the two genotypes were analyzed in an opaque white 96well plate. Samples were spotted in duplicate, and nontemplate controls were included in each plate. Two technical plate replicates were performed.

The relative expression ratio of the target gene versus the reference gene was calculated as $\mathrm{R} 0_{\mathrm{GOI}} / \mathrm{R} 0_{\mathrm{REF}}$, where $\mathrm{R} 0$ is the initial template concentration in each reaction. R0 was calculated using the formula $\mathrm{R} 0=1 /(1+\mathrm{E})^{\mathrm{Ct}}$, were $\mathrm{E}$ is the average efficiency of gene in the exponential phase and $\mathrm{Ct}$ is the threshold cycle (Zhao and Fernald 2005).

Analysis of defensive proteins. TI levels and PPO activity were measured in the leaf extracts following protocols described by Weech et al. (2008). For soluble protein extraction, ice-cold extraction buffer $\left(0.1 \mathrm{M}\right.$ sodium phosphate buffer, $\mathrm{NaH}_{2} \mathrm{PO}_{4}$, $\mathrm{pH} 7$, containing $0.1 \%$ triton- $\mathrm{X}$ and $7 \%$ polyvinylpyrrolidone) was added to finely ground leaf samples. After centrifugation at $15,700 \times g$ for $10 \mathrm{~min}$., the supernatant was transferred to a fresh tube. For the PPO assay, proteinase inhibitor cocktail $(0.5 \times)$ was added to extraction buffer to inhibit protein proteolysis.

The Bradford assay was performed to calculate the total soluble protein in the sample. A standard curve was generated, using bovine serum albumin ranging from 5 to $100 \mu \mathrm{g}$. Standards and samples were incubated with Bradford reagent (Fisher Scientific) for $10 \mathrm{~min}$, followed by $\mathrm{A}_{590}$ measurement of absorbance at $590 \mathrm{~nm}$ (Bradford 1976).

TI assay. Leaf soluble protein extracts were incubated with bovine trypsin $(0.5 \mu \mathrm{g})$ at $37^{\circ} \mathrm{C}$ for $20 \mathrm{~min}$ with constant shaking. The trypsin substrate $N$-benzoyo-L-arginyl$\beta$-nepthylamide hydrochloride (BANA; $2.6 \mathrm{mM}$ ) was added and samples were incubated for an additional $80 \mathrm{~min}$, with constant shaking. Trypsin cleaves BANA to release $\beta$-naphthalene. After the reaction was stopped by adding $\mathrm{HCl}(0.47 \%)$, pdimethyl-amino-cinnamaldehyde $(0.025 \%)$, which reacts with $\beta$-naphthalene, was added and the absorbance was read at $540 \mathrm{~nm}$. Samples were analyzed in triplicate. Also, a standard curve of soybean TI, type $1 \mathrm{~S}$ (ranging from $1 \mathrm{ng}$ to $5 \mu \mathrm{g}$ ), negative controls, and blanks were included in each plate.

PPO assay. Dimethyl formamide $(0.1 \%)$ and 3-methyl-2benzothiazolinone hydrazine $(0.2 \mathrm{mM})$ were added to triplicate soluble protein extracts. These compounds stabilize the reactive quinones that are produced by PPO. After the addition of substrate dopamine hydrochloride $(35 \mathrm{mM})$, reaction kinetics was measured at $476 \mathrm{~nm}$ every $10 \mathrm{~s}$ for $3 \mathrm{~min}$. The rate for the first $90 \mathrm{~s}$ was used for analysis. In addition, sodium dodecyl sulfate-treated and boiled samples (negative controls), tyrosinase (positive control), and blanks were included in each plate.

\section{Statistical analysis.}

A two-way analysis of variance (ANOVA) was used to analyze redox metabolites using SPSS (version 20) $(P \leq 0.05)$ (Supplementary Table 2). Since ET may affect plant growth and development, genotypes were analyzed separately (Benavente and Alonso 2006). When an interaction was detected (i.e., time $\times$ treatment), samples within each treatment were analyzed by one-way ANOVA, followed by a Tukey honest significant difference (HSD) posthoc test to identify the significant effect.

Gene expression, hormone levels, TI levels, and PPO activity were analyzed by one-way ANOVA within each genotype, followed by a Tukey HSD posthoc test to determine statistical differences $(P \leq 0.05)$ between treatments (Supplementary Table 3) (Rieu and Powers 2009). 


\section{ACKNOWLEDGMENTS}

We thank D. Cook (University of California, Davis) for the M. truncatula skl mutants. Acidic plant hormone analysis was conducted by the Proteomics \& Mass Spectroscopy Facility at the Danforth Plant Science Centre. We thank three anonymous reviewers for comments that substantially improved this paper. This project was supported by a Natural Sciences and Engineering Research Council (NSERC) grant to J. C. Bede.

\section{LITERATURE CITED}

Afshar, K., Dufresne, P. J., Pan, L., Merkx-Jacques, M., and Bede, J. C. 2010. Diet-specific salivary gene expression and glucose oxidase activity in Spodoptera exigua (Lepidoptera: Noctuidae) larvae. J. Insect Physiol. 56:1798-1806.

Anderson, J. P., and Singh, K. B. 2011. Interactions of Arabidopsis and M. truncatula with the same pathogens differ in dependence on ethylene and ethylene response factors. Plant Signal. Behav. 6:551-552.

Arimura, G., Garms, S., Maffei, M., Bossi, S., Schulze, B., Leitner, M., Mithöfer, A., and Boland, W. 2008. Herbivore-induced terpenoid emission in Medicago truncatula: Concerted action of jasmonate, ethylene and calcium signaling. Planta 227:453-464.

Arimura, G., Ozawa, R., and Maffei, M. E. 2011. Recent advances in plant early signaling in response to herbivory. Int. J. Mol. Sci. 12:3723-3739.

Ball, L., Accotto, G. P., Bechtold, U., Creissen, G., Funck, D., Jimenez, A., Kular, B., Leyland, N., Mejia-Carranza, J., Reynolds, H., Karpinski, S., and Mullineaux, P. M. 2004. Evidence for a direct link between glutathione biosynthesis and stress defense gene expression in Arabidopsis. Plant Cell $16: 2448-2462$

Bede, J. C., Musser, R. O., Felton, G. W., and Korth, K. L. 2006. Caterpillar herbivory and salivary enzymes decrease transcript levels of Medicago truncatula genes encoding early enzymes in terpenoid biosynthesis. Plant Mol. Biol. 60:519-531.

Benavente, L. M., and Alonso, J. M. 2006. Molecular mechanisms of ethylene signaling in Arabidopsis. Mol. Biosyst. 2:165-173.

Bradford, M. M. 1976. A rapid and sensitive method for the quantitation of microgram quantities of protein utilizing the principle of protein-dye binding. Anal. Biochem. 72:248-254.

Chamnongpol, S., Willekens, H., Moeder, W., Langebartels, C., Sandermann, H., Jr., Van Montagu, M., Inzé, D., and Van Camp, W. 1998. Defense activation and enhanced pathogen tolerance induced by $\mathrm{H}_{2} \mathrm{O}_{2}$ in transgenic tobacco. Proc. Natl. Acad. Sci. U.S.A. 95:5818-5823.

Cheng, Z., Sun, L., Qi, T., Zhang, B., Peng, W., Liu, Y., and Xie, D. 2011. The bHLH transcription factor MYC3 interacts with the jasmonate ZIM-domain proteins to mediate jasmonate response in Arabidopsis. Mol. Plant 4:279-288.

Chini, A., Fonseca, S., Fernández, G., Adie, B., Chico, J. M., Lorenzo, O., García-Casado, G., López-Vidriero, I., Lozano, F. M., Ponce, M. R., Micol, J. L., and Solano, R. 2007. The JAZ family of repressors is the missing link in jasmonate signalling. Nature 448:666-671.

Constabel, C. P., and Barbehenn, R. 2008. Defensive roles of polyphenol oxidase in plants. Pages 253-270 in: Induced Plant Resistance to Herbivory. Springer, Heidelberg, Germany.

Darwish, S. A., Pan, L., Ide, C., and Bede, J. C. 2008. Caterpillar-specific gene expression in the legume, Medicago truncatula. Plant Mol. Biol. Rep. 26:12-31.

Diezel, C., von Dahl, C. C., Gaquerel, E., and Baldwin, I. T. 2009. Different lepidopteran elicitors account for cross-talk in herbivory-induced phytohormone signaling. Plant Physiol. 150:1576-1586.

Dombrecht, B., Xue, G. P., Sprague, S. J., Kirkegaard, J. A., Ross, J. J., Reid, J. B., Fitt, G. P., Sewelam, N., Schenk, P. M., Manners, J. M., and Kazan, K. 2007. MYC2 differentially modulates diverse jasmonatedependent functions in Arabidopsis. Plant Cell 19:2225-2245.

Eichenseer, H., Mathews, M. C., Powell, J. S., and Felton, G. W. 2010. Survey of a salivary effector in caterpillars: Glucose oxidase variation and correlation with host range. J. Chem. Ecol. 36:885-897.

Espunya, M. C., De Michele, R., Gómez-Cadenas, A., and Martínez, M. C. 2012. $S$-nitrosoglutathione is a component of wound- and salicylic acidinduced systemic responses in Arabidopsis thaliana. J. Exp. Bot. 63: 3219-3227.

Felton, G. W. 2005. Indigestion is a plant's best defense. Proc. Natl. Acad. Sci. U.S.A. 102:18771-18772.

Felton, G. W., and Korth, K. L. 2000. Trade-offs between pathogen and herbivore resistance. Curr. Opin. Plant Biol. 3:309-314.

Fernández-Calvo, P., Chini, A., Fernández-Barbero, G., Chico, J.-M., Gimenez-Ibanez, S., Geerinck, J., Eeckhout, D., Schweizer, F., Godoy, M., Franco-Zorrilla, J. M., Pauwels, L., Witters, E., Puga, M. I., Paz-Ares, J.,
Goossens, A., Reymond, P., De Jaeger, G., and Solano, R. 2011. The Arabidopsis bHLH transcription factors MYC3 and MYC4 are targets of JAZ repressors and act additively with MYC2 in the activation of jasmonate responses. Plant Cell 23:701-715.

Forman, H. J., Maiorino, M., and Ursini, F. 2010. Signaling functions of reactive oxygen species. Biochemistry 49:835-842.

Foyer, C. H., and Noctor, G. 2011. Ascorbate and glutathione: The heart of the redox hub. Plant Physiol. 155:2-18.

Gao, L.-L., Anderson, J. P., Klingler, J. P., Nair, R. M., Edwards, O. R., and Singh, K. B. 2007. Involvement of the octadecanoid pathway in bluegreen aphid resistance in Medicago truncatula. Mol. Plant-Microbe Interact. 20:82-93.

Ghanta, S., Datta, R., Bhattacharyya, D., Sinha, R., Kumar, D., Hazra, S., Mazumdar, A. B., and Chattopadhyay, S. 2014. Multistep involvement of glutathione with salicylic acid and ethylene to combat environmental stress. J. Plant Physiol. 171:940-950.

Gomez, S. K., Cox, M. M., Bede, J. C., Inoue, K., Alborn, H. T., Tumlinson, J. H., and Korth, K. L. 2005. Lepidopteran herbivory and oral factors induce transcripts encoding novel terpene synthases in Medicago truncatula. Arch. Insect Biochem. Physiol. 58:114-127.

Halkier, B.A., and Gershenzon, J. 2006. Biology and biochemistry of glucosinolates. Annu. Rev. Plant Biol. 57:303-333.

Han, Y., Chaouch, S., Mhamdi, A., Queval, G., Zechmann, B., and Noctor, G. 2013. Functional analysis of Arabidopsis mutants points to novel roles for glutathione in coupling $\left.\left.\mathrm{H}_{2}\right) \mathrm{O}_{2}\right)$ to activation of salicylic acid accumulation and signaling. Antioxid. Redox Signal. 18:2106-2121.

Harfouche, A. L., Shivaji, R., Stocker, R., Williams, P. W., and Luthe, D. S. 2006. Ethylene signaling mediates a maize defense response to insect herbivory. Mol. Plant Microbe Interact. 19:189-199.

Jaouannet, M., Rodriguez, P. A., Thorpe, P., Lenoir, C. J. G., MacLeod, R., Escudero-Martinez, C., and Bos, J. I. 2014. Plant immunity in plant-aphid interactions. Front. Plant Sci. 5:663.

Kahl, J., Siemens, D. H., Aerts, R. J., Gäbler, R., Kühnemann, F., Preston, C. A., and Baldwin, I. T. 2000. Herbivore-induced ethylene suppresses a direct defense but not a putative indirect defense against an adapted herbivore. Planta 210:336-342.

Kamphuis, L. G., Zulak, K., Gao, L.-L., Anderson, J., and Singh, K. B. 2013. Plant-aphid interactions with a focus on legumes. Funct. Plant Biol. 40:1271-1284.

Koornneef, A., and Pieterse, C. M. J. 2008. Cross talk in defense signaling. Plant Physiol. 146:839-844.

Koornneef, A., Leon-Reyes, A., Ritsema, T., Verhage, A., Den Otter, F. C., Van Loon, L. C., and Pieterse, C. M. J. 2008. Kinetics of salicylatemediated suppression of jasmonate signaling reveal a role for redox modulation. Plant Physiol. 147:1358-1368.

Lan, Z., Krosse, S., Achard, P., van Dam, N.M., and Bede, J. C. 2014 DELLA proteins modulate Arabidopsis defences induced in response to caterpillar herbivory. J. Exp. Bot. 65:571-583.

Leon-Reyes, A., Spoel, S. H., De Lange, E. S., Abe, H., Kobayashi, M., Tsuda, S., Millenaar, F. F., Welschen, R. A. M., Ritsema, T., and Pieterse, C. M. J. 2009. Ethylene modulates the role of NONEXPRESSOR OF PATHOGENESIS-RELATED GENES1 in cross talk between salicylate and jasmonate signaling. Plant Physiol. 149:1797-1809.

Lorenzo, O., Piqueras, R., Sánchez-Serrano, J. J., and Solano, R. 2003. ETHYLENE RESPONSE FACTOR1 integrates signals from ethylene and jasmonate pathways in plant defense. Plant Cell 15:165-178.

Lorenzo, O., Chico, J. M., Sánchez-Serrano, J. J., and Solano, R. 2004. JASMONATE-INSENSITIVE1 encodes a MYC transcription factor essential to discriminate between different jasmonate-regulated defense responses in Arabidopsis. Plant Cell 16:1938-1950.

Maffei, M. E., Mithöfer, A., Arimura, G., Uchtenhagen, H., Bossi, S., Bertea, C. M., Starvaggi Cucuzza, L., Novero, M., Volpe, V., Quadro, S., and Boland, W. 2006. Effects of feeding Spodoptera littoralis on lima bean leaves. III. Membrane depolarization and involvement of hydrogen peroxide. Plant Physiol. 140:1022-1035.

Maffei, M. E., Arimura, G., and Mithöfer, A. 2012. Natural elicitors, effectors and modulators of plant responses. Nat. Prod. Rep. 29: 1288-1303.

Mateo, A., Funck, D., Mühlenbock, P., Kular, B., Mullineaux, P. M., and Karpinski, S. 2006. Controlled levels of salicylic acid are required for optimal photosynthesis and redox homeostasis. J. Exp. Bot. 57:1795-1807.

Maughan, S. C., Pasternak, M., Cairns, N., Kiddle, G., Brach, T., Jarvis, R., Haas, F., Nieuwland, J., Lim, B., Müller, C., Salcedo-Sora, E., Kruse, C., Orsel, M., Hell, R., Miller, A. J., Bray, P., Foyer, C. H., Murray, J. A. H., Meyer, A. J., and Cobbett, C. S. 2010. Plant homologs of the Plasmodium falciparum chloroquine-resistance transporter, PfCRT, are required for glutathione homeostasis and stress responses. Proc. Natl. Acad. Sci. U.S.A. 107:2331-2336. 
Merkx-Jacques, M., and Bede, J. C. 2005. Influence of diet on the larval beet armyworm, Spodoptera exigua, glucose oxidase activity. J. Insect Sci. 5:48. Mhamdi, A., Hager, J., Chaouch, S., Queval, G., Han, Y., Taconnat, L., Saindrenan, P., Gouia, H., Issakidis-Bourguet, E., Renou, J. P., and Noctor, G. 2010. Arabidopsis glutathione reductase1 plays a crucial role in leaf responses to intracellular hydrogen peroxide and in ensuring appropriate gene expression through both salicylic acid and jasmonic acid signaling pathways. Plant Physiol. 153:1144-1160.

Mitra, S., and Baldwin, I. T. 2014. RuBPCase activase (RCA) mediates growth-defense trade-offs: Silencing RCA redirects jasmonic acid (JA) flux from JA-isoleucine to methyl jasmonate (MeJA) to attenuate induced defense responses in Nicotiana attenuata. New Phytol. 201:1385-1395.

Møller, I. M., Jensen, P. E., and Hansson, A. 2007. Oxidative modifications to cellular components in plants. Annu. Rev. Plant Biol. 58:459-481.

Mou, Z., Fan, W., and Dong, X. 2003. Inducers of plant systemic acquired resistance regulate NPR1 function through redox changes. Cell 113: 935-944.

Musser, R. O., Hum-Musser, S. M., Eichenseer, H., Peiffer, M., Ervin, G., Murphy, J. B., and Felton, G. W. 2002. Herbivory: Caterpillar saliva beats plant defences. Nature 416:599-600.

Musser, R. O., Farmer, E., Peiffer, M., Williams, S. A., and Felton, G. W. 2006. Ablation of caterpillar labial salivary glands: Technique for determining the role of saliva in insect-plant interactions. J. Chem. Ecol. 32:981-992.

Ndamukong, I., Abdallat, A. A., Thurow, C., Fode, B., Zander, M., Weigel, R., and Gatz, C. 2007. SA-inducible Arabidopsis glutaredoxin interacts with TGA factors and suppresses JA-responsive PDF1.2 transcription. Plant J. 50:128-139.

Noctor, G., Mhamdi, A., Chaouch, S., Han, Y., Neukermans, J., MarquezGarcia, B., Queval, G., and Foyer, C. H. 2012. Glutathione in plants: An integrated overview. Plant Cell Environ. 35:454-484.

Oldroyd, G. E., and Downie, J. A. 2008. Coordinating nodule morphogenesis with rhizobial infection in legumes. Annu. Rev. Plant Biol. 59:519-546.

Orozco-Cárdenas, M. L., Narváez-Vásquez, J., and Ryan, C. A. 2001. Hydrogen peroxide acts as a second messenger for the induction of defense genes in tomato plants in response to wounding, systemin, and methyl jasmonate. Plant Cell 13:179-191.

Pan, X., Welti, R., and Wang, X. 2010. Quantitative analysis of major plant hormones in crude plant extracts by high-performance liquid chromatographymass spectrometry. Nat. Protoc. 5:986-992.

Parisy, V., Poinssot, B., Owsianowski, L., Buchala, A., Glazebrook, J., and Mauch, F. 2007. Identification of PAD2 as a $\gamma$-glutamylcysteine synthetase highlights the importance of glutathione in disease resistance of Arabidopsis. Plant J. 49:159-172.

Paudel, J., Copley, T., Amirizian, A., Prado, A., and Bede, J. C. 2013. Arabidopsis redox status in response to caterpillar herbivory. Front. Plant Sci. 4:113.

Pauly, N., Pucciariello, C., Mandon, K., Innocenti, G., Jamet, A., Baudouin, E., Hérouart, D., Frendo, P., and Puppo, A. 2006. Reactive oxygen and nitrogen species and glutathione: Key players in the legume-Rhizobium symbiosis. J. Exp. Bot. 57:1769-1776.

Pauwels, L., Barbero, G. F., Geerinck, J., Tilleman, S., Grunewald, W., Pérez, A. C., Chico, J. M., Bossche, R. V., Sewell, J., Gil, E., GarcíaCasado, G., Witters, E., Inzé, D., Long, J. A., De Jaeger, G., Solano, R., and Goossens, A. 2010. NINJA connects the co-repressor TOPLESS to jasmonate signalling. Nature 464:788-791.

Penmetsa, R. V., and Cook, D. R. 1997. A legume ethylene-insensitive mutant hyperinfected by its rhizobial symbiont. Science 275:527-530.

Penmetsa, R. V., Uribe, P., Anderson, J., Lichtenzveig, J., Gish, J. C., Nam, Y. W., Engstrom, E., Xu, K., Sckisel, G., Pereira, M., Baek, J. M., LopezMeyer, M., Long, S. R., Harrison, M. J., Singh, K. B., Kiss, G. B., and Cook, D. R. 2008. The Medicago truncatula ortholog of Arabidopsis EIN2, sickle, is a negative regulator of symbiotic and pathogenic microbial associations. Plant J. 55:580-595.

Petersen, M., Brodersen, P., Naested, H., Andreasson, E., Lindhart, U., Johansen, B., Nielsen, H. B., Lacy, M., Austin, M. J., Parker, J. E., Sharma, S. B., Klessig, D. F., Martienssen, R., Mattsson, O., Jensen, A. B., and Mundy, J. 2000. Arabidopsis map kinase 4 negatively regulates systemic acquired resistance. Cell 103:1111-1120.

Pieterse, C. M. J., Leon-Reyes, A., Van der Ent, S., and Van Wees, S. C. M. 2009. Networking by small-molecule hormones in plant immunity. Nat. Chem. Biol. 5:308-316.

Pieterse, C. M. J., Van der Does, D., Zamioudis, C., Leon-Reyes, A., and Van Wees, S. C. M. 2012. Hormonal modulation of plant immunity. Annu. Rev. Cell Dev. Biol. 28:489-521.

Pieterse, C. M. J., Poelman, E. H., Van Wees, S. C. M., and Dicke, M. 2013. Induced plant responses to microbes and insects. Front. Plant Sci. $4: 475$
Pré, M., Atallah, M., Champion, A., De Vos, M., Pieterse, C. M. J., and Memelink, J. 2008. The AP2/ERF domain transcription factor ORA59 integrates jasmonic acid and ethylene signals in plant defense. Plant Physiol. 147:1347-1357.

Quan, L. J., Zhang, B., Shi, W. W., and Li, H. Y. 2008. Hydrogen peroxide in plants: A versatile molecule of the reactive oxygen species network. J. Integr. Plant Biol. 50:2-18.

Queval, G., and Noctor, G. 2007. A plate reader method for the measurement of NAD, NADP, glutathione, and ascorbate in tissue extracts: Application to redox profiling during Arabidopsis rosette development. Anal. Biochem. 363:58-69.

Rahman, I., Kode, A., and Biswas, S. K. 2006. Assay for quantitative determination of glutathione and glutathione disulfide levels using enzymatic recycling method. Nat. Protoc. 1:3159-3165.

Rieu, I., and Powers, S. J. 2009. Real-time quantitative RT-PCR: Design, calculations, and statistics. Plant Cell 21:1031-1033.

Schlaeppi, K., Bodenhausen, N., Buchala, A., Mauch, F., and Reymond, P. 2008. The glutathione-deficient mutant pad2-1 accumulates lower amounts of glucosinolates and is more susceptible to the insect herbivore Spodoptera littoralis. Plant J. 55:774-786.

Spoel, S. H., and Loake, G. J. 2011. Redox-based protein modifications: The missing link in plant immune signalling. Curr. Opin. Plant Biol. 14:358-364

Spoel, S. H., Koornneef, A., Claessens, S. M. C., Korzelius, J. P., Van Pelt, J. A., Mueller, M. J., Buchala, A. J., Métraux, J. P., Brown, R., Kazan, K., Van Loon, L. C., Dong, X., and Pieterse, C. M. J. 2003. NPR1 modulates cross-talk between salicylate- and jasmonate-dependent defense pathways through a novel function in the cytosol. Plant Cell 15:760-770.

Staswick, P. E., and Tiryaki, I. 2004. The oxylipin signal jasmonic acid is activated by an enzyme that conjugates it to isoleucine in Arabidopsis. Plant Cell 16:2117-2127.

Stotz, H. U., Pittendrigh, B. R., Kroymann, J., Weniger, K., Fritsche, J., Bauke, A., and Mitchell-Olds, T. 2000. Induced plant defense responses against chewing insects. Ethylene signaling reduces resistance of Arabidopsis against Egyptian cotton worm but not diamondback moth. Plant Physiol. 124:1007-1018.

Thines, B., Katsir, L., Melotto, M., Niu, Y., Mandaokar, A., Liu, G., Nomura, K., He, S. Y., Howe, G. A., and Browse, J. 2007. JAZ repressor proteins are targets of the SCF ${ }^{\mathrm{COI}}$ complex during jasmonate signalling. Nature 448:661-665.

Tian, D., Peiffer, M., De Moraes, C. M., and Felton, G. W. 2014. Roles of ethylene and jasmonic acid in systemic induced defense in tomato (Solanum lycopersicum) against Helicoverpa zea. Planta 239:577-589.

Tretner, C., Huth, U., and Hause, B. 2008. Mechanostimulation of Medicago truncatula leads to enhanced levels of jasmonic acid. J. Exp. Bot. 59: 2847-2856.

Vandenabeele, S., Van Der Kelen, K., Dat, J., Gadjev, I., Boonefaes, T., Morsa, S., Rottiers, P., Slooten, L., Van Montagu, M., Zabeau, M. Inze, D., and Van Breusegem, F. 2003. A comprehensive analysis of hydrogen peroxide-induced gene expression in tobacco. Proc. Natl. Acad. Sci. U.S.A. 100:16113-16118.

Verhage, A., Vlaardingerbroek, I., Raaymakers, C., Van Dam, N. M., Dicke, M., Van Wees, S. C. M., and Pieterse, C. M. J. 2011. Rewiring of the jasmonate signaling pathway in Arabidopsis during insect herbivory. Front. Plant Sci. 2:47.

Voelckel, C., Schittko, U., and Baldwin, I. T. 2001. Herbivore-induced ethylene burst reduces fitness costs of jasmonate- and oral secretioninduced defenses in Nicotiana attenuata. Oecologia 127:274-280.

Vos, I. A., Verhage, A., Schuurink, R. C., Watt, L. G., Pieterse, C. M. J., and Van Wees, S. C. M. 2013. Onset of herbivore-induced resistance in systemic tissue primed for jasmonate-dependent defenses is activated by abscisic acid. Front. Plant Sci. 4:539.

Walling, L. L. 2008. Avoiding effective defenses: Strategies employed by phloem-feeding insects. Plant Physiol. 146:859-866.

Wang, K. L. C., Li, H., and Ecker, J. R. 2002. Ethylene biosynthesis and signaling networks. Plant Cell 14 (Suppl):S131-S151.

Weech, M. H., Chapleau, M., Pan, L., Ide, C., and Bede, J. C. 2008. Caterpillar saliva interferes with induced Arabidopsis thaliana defence responses via the systemic acquired resistance pathway. J. Exp. Bot. 59:2437-2448.

Winz, R. A., and Baldwin, I. T. 2001. Molecular interactions between the specialist herbivore Manduca sexta (Lepidoptera, Sphingidae) and its natural host Nicotiana attenuata. IV. Insect-Induced ethylene reduces jasmonate-induced nicotine accumulation by regulating putrescine $\mathrm{N}$ methyltransferase transcripts. Plant Physiol. 125:2189-2202.

Xu, L., Liu, F., Lechner, E., Genschik, P., Crosby, W. L., Ma, H., Peng, W., Huang, D., and Xie, D. 2002. The SCF $\left(^{\mathrm{COI1}}\right.$ ) ubiquitin-ligase complexes are required for jasmonate response in Arabidopsis. Plant Cell 14:1919-1935.

Xu, J., Li, Y., Wang, Y., Liu, H., Lei, L., Yang, H., Liu, G., and Ren, D. 2008. Activation of MAPK kinase 9 induces ethylene and camalexin 
biosynthesis and enhances sensitivity to salt stress in Arabidopsis. J. Biol. Chem. 283:26996-27006.

Yan, J., Zhang, C., Gu, M., Bai, Z., Zhang, W., Qi, T., Cheng, Z., Peng, W., Luo, H., Nan, F., Wang, Z., and Xie, D. 2009. The Arabidopsis coronatine insensitivel protein is a jasmonate receptor. Plant Cell 21:2220-2236.

Yoo, S. D., Cho, Y., and Sheen, J. 2009. Emerging connections in the ethylene signaling network. Trends Plant Sci. 14:270-279.

Zander, M., Thurow, C., and Gatz, C. 2014. TGA transcription factors activate the salicylic acid-suppressible branch of the ethylene-induced defense program by regulating ORA59 expression. Plant Physiol. 165:1671-1683.

Zhao, S., and Fernald, R. D. 2005. Comprehensive algorithm for quantitative real-time polymerase chain reaction. J. Comput. Biol. 12:1047-1064.
Zhao, Q., and Guo, H.-W. 2011. Paradigms and paradox in the ethylene signaling pathway and interaction network. Mol. Plant 4:626-634.

Zhu, Z. 2014. Molecular basis for jasmonate and ethylene signal interactions in Arabidopsis. J. Exp. Bot. 65:5743-5748.

Zhu, Z., An, F., Feng, Y., Li, P., Xue, L., A, M., Jiang, Z., Kim, J.-M., To, T. K., Li, W., Zhang, X., Yu, Q., Dong, Z., Chen, W. Q., Seki, M., Zhou, J. M., and Guo, H. 2011. Derepression of ethylene-stabilized transcription factors (EIN3/EIL1) mediates jasmonate and ethylene signaling synergy in Arabidopsis. Proc. Natl. Acad. Sci. U.S.A. 108:12539-12544.

Zhu-Salzman, K., Luthe, D. S., and Felton, G. W. 2008. Arthropodinducible proteins: Broad spectrum defenses against multiple herbivores. Plant Physiol. 146:852-858. 